\title{
Performance improvements of auxiliary drives for automotive pump and fan applications
}

\author{
A. Muetze, S. Leitner, H. Gruebler, F. Krall
}

The need to increase electrification in the automotive industry has been well recognized. Overshadowed by their larger counterparts used for the car's traction is the increasing number of small electric drives used in automotive applications. As a matter of fact, up to 100 of such drives are used within a typical mid-sized car. This includes performance-, safety-, and comfort-related auxiliary drives, of which around $10 \%$ are used as parts of pumping and fan systems. With such "small drives," i.e., fractional horsepower (FHP) drives at the lower end of the power spectrum, volume, mass, and efficiency have so far only been attributed secondary importance. Yet, the increasing demands on the automotive industry have also resulted in renewed interest not only in the performance parameters of these auxiliary drives, such as energy conversion efficiency, size, and cost, but also in electromagnetic emission, noise, and fault tolerance. This survey article presents selected results on recent achievements in these rather new fields of research and outlines fundamental research questions.

Keywords: auxiliary drives; brushless motor; efficiency; fan drives; fractional horsepower; low-cost; variable speed drives

Verbesserung der Performance von Hilfsantrieben für Pumpen- und Lüfteranwendungen in automotiven Anwendungen.

Im Zuge der Elektrifizierung der Automobilindustrie wird eine zunehmende Anzahl kleiner elektrischer Antriebe als Hilfsantriebe eingesetzt. Bis zu 100 solcher Antriebe finden sich in einem typischen Mittelklassewagen. Diese erfüllen Funktionen des Fahrverhaltens, der Fahrsicherheit, oder - zunehmend - des Komforts. Rund $10 \%$ dieser Antriebe werden in Pumpen- und Lüftersystemen eingesetzt. Bei solch "kleinen Antrieben", sogenannten FHP(fractional horsepower)-Antrieben am unteren Ende des Leistungsspektrums, spielten Volumen, Masse und Wirkungsgrad bislang nur eine untergeordnete Rolle. Die steigenden Anforderungen an die Automobilindustrie haben jedoch nicht nur das Interesse an diesen konventionellen Leistungsparametern, sondern auch an anderen Performance Parametern wie elektromagnetische Emissionen, Geräuschentwicklung und Fehlertoleranz, erhöht. Dieser Übersichtsartikel skizziert damit in Zusammenhang stehende grundlegende Forschungsfragen und präsentiert ausgewählte Ergebnisse aus diesen eher neuen Forschungsfeldern.

Schlüsse/wörter: Bürstenlose Motoren; drehzahlvariable Antriebe; Hilfsantriebe; Kleinantriebe; Lüfterantriebe; Niedrigkostenprinzip; Wirkungsgrad

Received January 15, 2020, accepted April 2, 2020, published online April 23, 2020

(C) The Author(s) 2020

\section{Introduction}

For most, the current trend "transportation electrification," driven by climate change and concerns on resources, relates to the replacement of the conventional combustion engine(s) with modern power-electronics based electric drive systems. Yet, such electrification also applies to the less visible auxiliary drive systems that relate to the performance, safety, and comfort of the overall system, in which electric drives have been replacing conventional hydraulic systems. Examples of such systems include heat pumpbased thermal systems for electric vehicles [1], electromechanical brake boosters [2], electric water pumps for engine cooling [3], electric oil pumps for gearbox lubrication to avoid hydraulic drag losses [4], and LED-headlight fans for cooling and dehumidification [5].

The number of auxiliary drives in use in traction systems has increased further as the demands on the safety and comfort of transportation, notably within the automotive industry, have continuously become more stringent in recent years. Taking an average mid-sized passenger car as an example, some 100 auxiliary drives are used for different functions, which relate to the performance, safety, and comfort of the car, as illustrated in Fig. 1. Almost three-fourth of these drives are comfort-related. To illustrate this point, Table 1 shows the number of auxiliary drives used to increase the comfort of the Mercedes S-Class in 2013, as published in [6]. This clearly mirrors not only the significant absolute number of auxiliary drives, but also the large portion of such drives used for comfort related functions, such as the ventilation and air cooling system or the magnetic valves for the massage seat.

Muetze, Annette, Christian Doppler Laboratory for Brushless Drives for Pump and Fan Applications, Electric Drives and Machines Institute, Graz University of Technology, Inffeldgasse 18/l, 8010 Graz, Austria (E-mail: muetze@tugraz.at); Leitner, Stefan, Christian Doppler Laboratory for Brushless Drives for Pump and Fan Applications, Electric Drives and Machines Institute, Graz University of Technology, Inffeldgasse 18/l, $8010 \mathrm{Graz}$, Austria (E-mail: s.leitner@tugraz.at); Gruebler, Hannes, Christian Doppler Laboratory for Brushless Drives for Pump and Fan Applications, Electric Drives and Machines Institute, Graz University of Technology, Inffeldgasse 18//, $8010 \mathrm{Graz}$, Austria (E-mail: hannes.gruebler@tugraz.at); Krall, Felix, Christian Doppler Laboratory for Brushless Drives for Pump and Fan Applications, Electric Drives and Machines Institute Graz University of Technology, Inffeldgasse 18/l, $8010 \mathrm{Graz}$, Austria (E-mail: felix.krall@tugraz.at) 


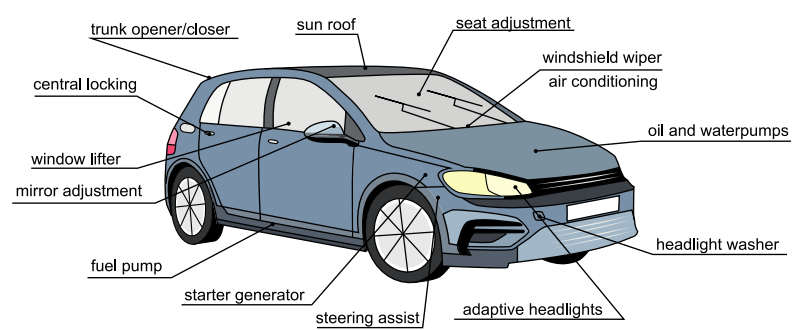

Fig. 1. Examples of use of auxiliary drives in a mid-size passenger car; picture credit: D. Klein

Table 1. Number of auxiliary drives to increase the comfort of the Mercedes S-Class in 2013, as published in [6]

\begin{tabular}{ll}
\hline Function & Quantity \\
\hline Ventilation, air conditioning system & 22 \\
Seat actuator & 54 \\
Steering wheel adjustment & 2 \\
Magnetic valves for massage seat (two seats) & 28 \\
Window lifter & 4 \\
Exterior mirror & 5 \\
Door and tailgate closer & 5 \\
Sound system (tweeter adjustment) & 2 \\
Steering wheel vibrator & 1 \\
Fan (main display) & 1 \\
Sunroof and window shade & 5 \\
Seat belt bringer and stretcher & 4 \\
DVD-deck & 2 \\
\hline
\end{tabular}

\section{Increasingly demanding operating requirements on the} auxiliary drives

As the drives are used for different purposes, the demands on the drives may vary, with emphasis on one or the other performance criteria, such as reliability or cost. Considering the different functions for which the auxiliary drives are used, three types of such auxiliary drives may be distinguished between:

1. Performance-related drives,

2. Safety-related drives, and

3. Comfort-related drives

While performance-related drives are directly linked to the engine or power train, safety-related drives are directly or indirectly connected to the car's drivability and handling, whereas comfort-related drives are not necessary for the functioning of the car, but do enhance the driving experience. Examples for the different categories are given by the oil pump or the engine cooling pump, by the windshield wipers or the LED-headlight cooling and dehumidification fan (e.g., see Fig. 2), or by ventilation and air conditioning or seat actuators, respectively.

These auxiliary drives all have rated powers in the FHP, or even sub-FHP range, and thus are not subject to standardization. In contrast to "larger" drives, where even so-called customized solutions often revert to modular building blocks, these small drives are developed for each case of utilization, which is, in turn, often a massapplication. The continuing decrease of the length of product development cycles over the recent years has called for new design and development tools.

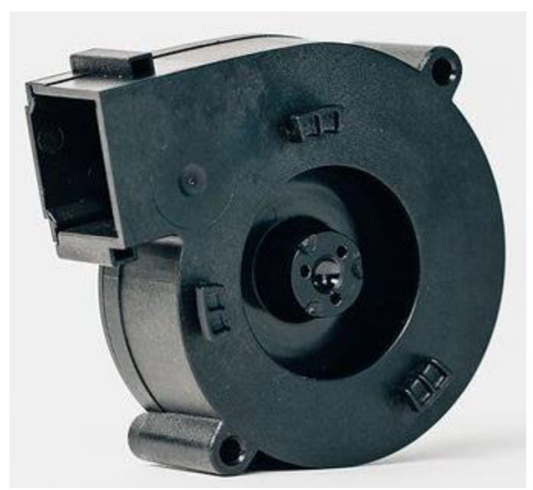

Fig. 2. Radial fan drive for LED-headlight cooling and dehumidification; @MSG Mechatronic Systems GmbH

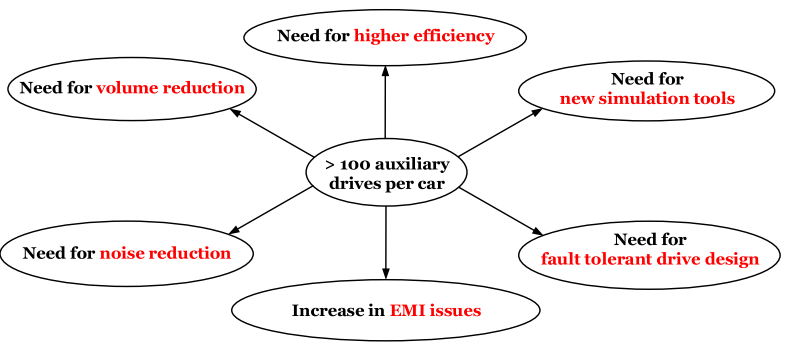

Fig. 3. Research problems with modern auxiliary drives for automotive pump and fan applications

As inherent with mass-applications, cost has long been (and often still is) the main design factor, as long as the requirements on the functionality of the product are met. Thus, other performance parameters, such as energy conversion efficiency, fluctuating power and torque, electromagnetic compatibility, and fault-tolerance have often been compromised. Depending on the application, these aspects may then be addressed at the system level in a form of retrofit, such as the modification of the mechanical structure to reduce noise, or the use of additional filters to reduce electromagnetic emissions.

With the continuing price-drop of electronics, electronics-based brushless motors have recently been replacing their brushed counterparts, notably for long-term applications, such as ventilation or pumping systems. The increasing demands of the customer on the drive performance significantly affect such drives. Thus, a large field of research is opening up that is yet to be addressed, see Fig. 3 .

The following sections present selected results on recent achievements in these fields of research, including

- small drive design aspects,

- drive system modeling,

- cogging torque reduction,

- performance improvement through drive control, and

- noise development.

\section{Small drive design aspects}

\subsection{Electric machine}

When compared with the design of "larger" machines, specific design criteria apply, by and large, to the FHP and sub-FHP drives which are of interest for the pump and fan applications in question here:

- FHP drives have small electric time constants due to their geometry-related low inductance and high resistance. 
- FHP drives often have outer rotor motors because the winding can easily be wound from the outside using linear or flyer winders instead of needle winders.

- FHP fan drives typically feature outer rotor motors in which the impeller is directly integrated with the rotor, making optimum use of all available space and ensuring a smooth operation due to the increased inertia.

- FHP pump drives are typically implemented with wet-runners to omit a shaft seal having inner rotor motors due to the reduced viscous friction torque.

- Despite their inherent lower efficiency and fluctuating output power, single-phase machines are often preferred over threephase variants due to the significantly reduced manufacturing cost.

- FHP drives generally have large cogging torque (due to suboptimal slot-pole combinations) and torque ripple (because of the cogging torque and also commutation torque ripple as well as inherent torque ripple due to the nonideal voltage and current waveforms).

- In single-phase drives, bifilar windings are often preferred over their unifilar counterparts due to the reduced count of power electronic switches (two instead of four) and the use of the more cost-effective low-side drivers.

- When dimensions become very small, it can be advantageous to punch and bend steel sheets to achieve a claw-pole stator which has only one simple ring winding

- The application of established methods to reduce the cogging torque (e.g., skewing) is limited for very small drives due to increased cost and manufacturing challenges.

- Small components are typically more vulnerable to manufacturing tolerances and their influence on the performance.

- The relative air-gap is larger compared to integral horsepower electric machines reducing the efficiency.

\subsection{Electronics}

The constant increase in the number of control units in modern cars calls for a decrease in the complexity of the control of auxiliary systems themselves so as to reduce the risk of failure. Aiming to reduce the component count, application specific integrated circuits (ASICS) that only provide the functions absolutely necessary for an application are used (see Fig. 4), in contrast to common universal solutions with microcontrollers. Typically, state-of-the art solutions of single-phase and three-phase FHP brushless motors for pump and fan applications are used.

The number of appropriate driver circuits is limited because of the automotive industry's special requirements, such as the compliance to the "Stress Test Qualification for Integrated Circuits" specification by the Automotive Electronics Council (AEC) AEC-Q100. This, in turn, significantly influences the motor design, since the specific characteristics of the circuit, such as certain (minimum) levels of the back EMF and current limits, directly influence the motor design. In addition, integrating the switches with the control circuit on one chip can significantly increase the on-state resistance and hence the losses. In contrast, in-house development of the electronics and hence customized design may allow further performance improvement.

\section{Drive system modeling}

\subsection{New tools for shorter system development cycles}

As electric machines have been designed for many years, also new design questions are typically addressed in in-house, experience-

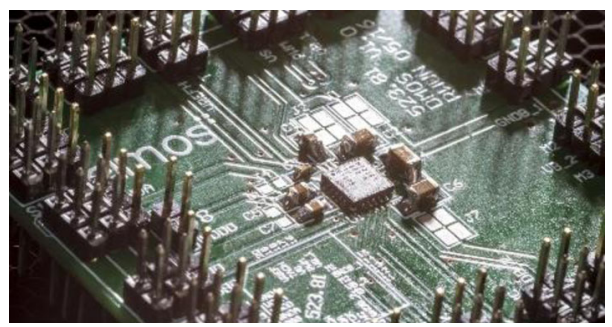

Fig. 4. Sensorless motorcontroller with integrated power bridge up to $500 \mathrm{~mA}(\mathrm{rms})$ in an QFN5 housing [7]; picture credit: Lunghammer-TU Graz

based approaches within the established companies. Often, the design requirements conflict, and for each application, a trade-off between the extents to which these different aims are met must be made. Performance spaces can describe such relationships, but they can only be computed if the relevant, underlying models are available, and if the different possible drive system topologies and operating possibilities have been investigated.

Modeling all the different characteristics of interest requires multiphysics simulations, which may be very time-consuming. Often, the mutual interaction between the motor and the electronics is only investigated in subsequent steps. Thus, the system optimization is reduced to the optimization of the individual components under the constraints of the other. As for the design of FHP and sub-FHP machines, mostly time-consuming brute-force 3D finite element analysis (FEA) together with experience-based trial and error are used to consider the aspect ratios specific for these drives. This contrasts the need for rapid system evaluation as required by the decreasing of the product development cycles' length.

Approximation-based approaches have gained attention as they bridge the gap between analytic and numerical approaches in manifold engineering disciplines [8-11]. Examples of such approaches are kriging, response surface, space mapping, and artificial neural networks [12-14]. The setup of these models requires some training, and the models are then valid for a certain parameter space and topology, as it may by given by a certain FHP drive. The application of space mapping for modeling the overall machine is exemplarily outlined in the following. This model can then be amended by refined submodels, as shown by iron loss loss-surface modeling and modeling of the leakage paths in FHP PM machines.

\subsection{Space mapping}

Space mapping splits optimization and validation into a coarse and a fine model of the system. It thus allows using simple models both for the optimization and for the multi-physics simulations. Thereby, it jointly accelerates the design process while allowing searches in a larger parameter space at reasonable computational effort and thus time.

The applicability of this approach is illustrated for a small PM outer rotor brushless motor [15]. The corresponding coarse and fine models, as well as a picture of a prototype, are shown in Fig. 5. The evaluation time $t_{\text {eval }}$ and the efficiency $\eta$ of the different models are used for comparison, quantified by the respective differences $\Delta t_{\text {eval }}$ and $\Delta \eta$. For $\Delta t_{\mathrm{eval}}$, the baseline is the analytic model's evaluation time, whereas $\Delta \eta$ is compared with respect to the efficiency computed by the 3D-FEA model that has been validated experimentally. As per Table 2, the surrogate model produced the same results as the time consuming 3D-FEA for one particular design option, at evaluation times of only fractions of a second. 
(a)

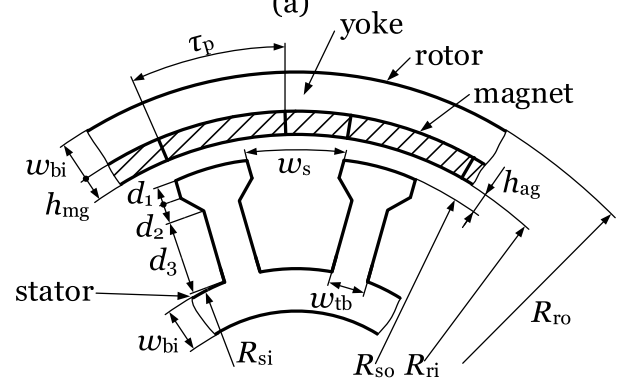

(b)

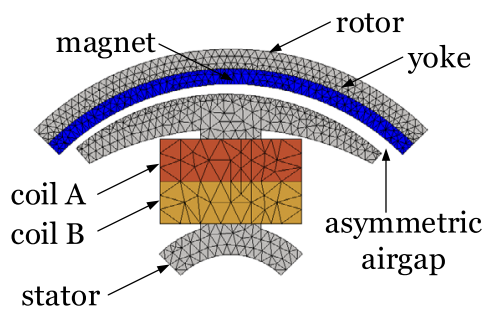

(c)

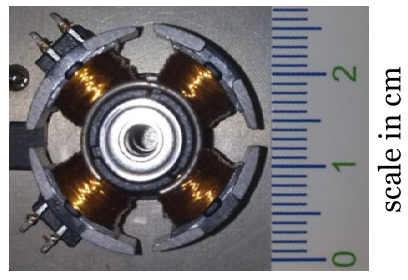

Fig. 5. (a) coarse model (sketch with geometric parameters), (b) fine model (quarter 3D finite element model of the motor due to symmetries), and (c) picture of a prototype of the investigated single-phase outer rotor brushless drive motor (solely stator and windings visible) [15]

(a)

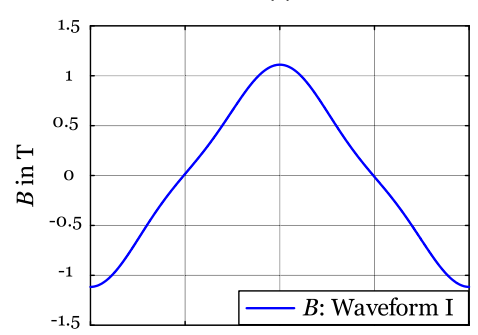

(b)

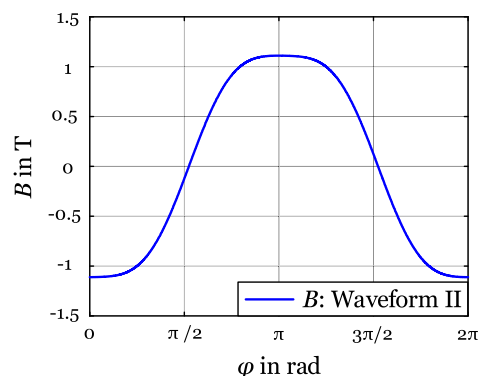

(c)

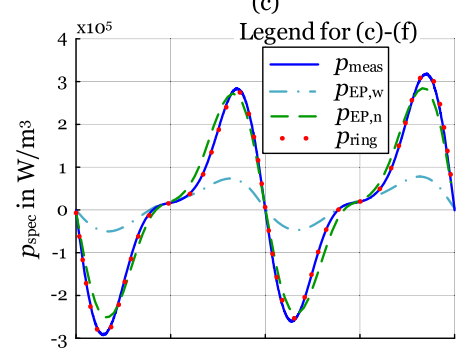

(d)

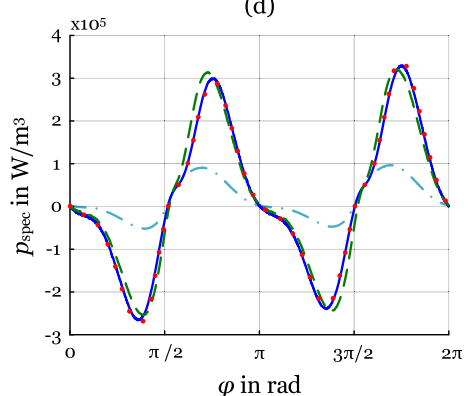

(e)

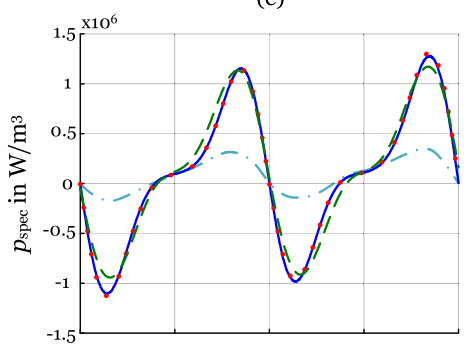

(f)

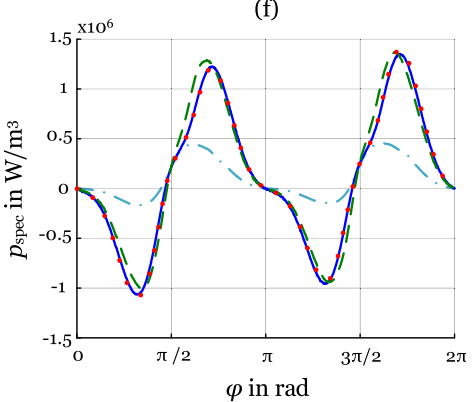

Fig. 6. Waveforms of flux density (a)-(b), instantaneous losses for $f=50 \mathrm{~Hz}$ (c)-(d), and for $f=200 \mathrm{~Hz}$ (e)-(f) in the toroidal lamination stack for the respective waveforms [16]

Table 2. Evaluation results of the underlying models of the space mapping modeling approach for a selected operating point at 5000 rpm [15]

\begin{tabular}{lllll}
\hline Model & $t_{\text {eval }}$ & $\Delta t_{\text {eval }}$ & $\eta$ & $\Delta \eta$ \\
\hline- & hh:mm:ss & times & $\%$ & $\%$ \\
\hline Analytic & $00: 00: 00.33$ & - & 47.2 & 1.1 \\
Surrogate & $00: 00: 00.35$ & 1.06 & 46.7 & - \\
2D-FEA & $00: 01: 09$ & 209 & 42.5 & -8.9 \\
3D-FEA & $17: 28: 21$ & $1.9 \cdot 10^{5}$ & 46.7 & - \\
\hline
\end{tabular}

Although the difference in performance between the analytic model and the 3D-FEA is rather small, the analytic model is not able to cover nonlinear behavior; the surrogate model, however, trained with several such supporting points, is able to do so. In addition, the surrogate model allows for the straightforward analysis of the effects of selected input parameter on one or several output parameters, as an alternative to time consuming 3D-FEA and their computation over a wide parameter range.
The output data of the surrogate model can be used as parts of multi-physical models, for example, coupled with electric circuit simulators. This, in turn, allows for the desired comprehensive performance analysis within acceptable times, such as the computation of drive system efficiency maps or development of performance spaces for given design spaces.

4.3 Iron loss computation based on the loss-surface method The loss-surface method allows for the consideration of the influence of the different manufacturing and operating characteristics, such as the strongly non-sinusoidal flux density waveforms, the temperature, and mechanical stress occurring during the manufacturing process $[16,17]$. It is based on preliminary measurements of the losses occurring for data points $(B, d B / d t)$ over a certain range of flux densities $B$ and rates of change of flux density $d B / d t$, from which the loss surface is obtained. It is significantly more accurate than the common approaches based on empirical factors, which are often solely available for larger machines [18]. The samples from which the loss-surface is obtained need to be carefully prepared so as to mirror the final machine. For example, in FHP machines, the eddy 
Table 3. Measured and predicted mean iron loss densities of a toroidal lamination stack [16]; $P_{E \mathrm{EP}, \mathrm{w}}$ and $\boldsymbol{P}_{\mathrm{EP}, \mathrm{n}}$ are based on loss-surfaces determined from Epstein frame samples with wide $\left(\boldsymbol{P}_{\mathrm{EP}, \mathrm{w}}\right.$, width of the strips: $\left.30 \mathrm{~mm}\right)$ and narrow $\left(\boldsymbol{P}_{\mathrm{EP}, \mathrm{n}}\right.$, width of the strips: $\left.5 \mathrm{~mm}\right)$ strips. $\boldsymbol{P}_{\text {ring }}$ is obtained from a loss-surface based on the toroidal iron stack

\begin{tabular}{|c|c|c|c|c|c|c|c|c|}
\hline $\begin{array}{l}\text { Waveform } \\
-\end{array}$ & $\begin{array}{l}f_{\mathrm{B}} \\
\mathrm{Hz}\end{array}$ & $\begin{array}{l}P_{\text {meas }} \\
\frac{\mathrm{kW}}{\mathrm{m}^{3}}\end{array}$ & $\begin{array}{l}P_{E P, w} \\
\frac{k W}{m^{3}}\end{array}$ & $\begin{array}{l}P_{\mathrm{EP}, \mathrm{n}} \\
\frac{\mathrm{kW}}{\mathrm{m}^{3}}\end{array}$ & $\begin{array}{l}P_{\text {ring }} \\
\frac{\mathrm{kW}}{\mathrm{m}^{3}}\end{array}$ & $\begin{array}{l}e_{E P, w} \\
\%\end{array}$ & $\begin{array}{l}e_{E P, n} \\
\%\end{array}$ & $\begin{array}{l}e_{\text {ring }} \\
\%\end{array}$ \\
\hline I & 50 & 15.66 & 14.17 & 17.53 & 16.1 & -9.5 & 11.9 & 2.8 \\
\hline I & 200 & 91.08 & 83.99 & 109.01 & 95.25 & -7.8 & 19.7 & 4.6 \\
\hline$\|$ & 50 & 16.82 & 15.67 & 19.47 & 17.5 & -6.8 & 15.8 & 4.0 \\
\hline$\|$ & 200 & 111.13 & 98.1 & 131.46 & 113.41 & -11.7 & 18.3 & 2.1 \\
\hline
\end{tabular}

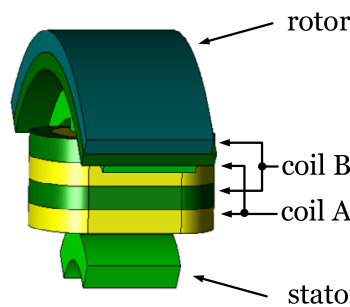

(a) (b)

Fig. 7. 3D-FEA models of the example case FHP motor; (a) with roto overhang, (b) without rotor overhang; the back EMF computed from the 3D model without rotor overhang is equivalent to the computed one from the 2D-FEA model, confirming the important role of the rotor overhang; [19]

currents occurring due to the iron sheets' stacking have proven to play a central role in the final results.

Table 3 compares three mean iron loss densities of a toroidal lamination stack that have been determined from different loss-surfaces, $P_{\mathrm{EE}, \mathrm{W}}, P_{\mathrm{EP}, \mathrm{n}}$, and $P_{\text {ring }}$, and compares it with the directly measured reference loss density $P_{\text {meas }}$. Two different waveforms, sinusoidal signals with an additional third harmonic component $30 \%$ of the main amplitude, $180^{\circ}$ and $0^{\circ}$ phase shift for waveform I and II, respectively) with frequencies of 50 and $200 \mathrm{~Hz}$, are chosen for evaluation. The different waveforms and measured losses are shown in Fig. 6 . The results show a certain immunity to change of frequency and waveform of magnetic flux density. On the other hand, the preparation of the samples (e.g., material degradation due to cutting, shown by the significant difference between wide and narrow Epstein samples in Fig. 6), used to determine the respective losssurfaces, has a significant impact.

\subsection{Investigation of flux stray paths in FHP machines}

The stray paths of FHP machines, too, are significantly more influenced by data uncertainty than in the case of larger machines. Furthermore, the specific aspect ratios do not allow the use of the correction factors established for larger machines.

Exemplarily, Fig. 7 shows two 3D-FEA models of the example case motor, one with the realized rotor overhang, one without. The 3D model with a modeled winding overhang but without the rotor overhang produced the same results for the computed back EMF as the 2D-FEA model (not shown in Fig. 7), illustrating the importance of 3D-FEA in considering such details as rotor overhang. This error is as large as $25 \%$, see Fig. 8 .

As a further example, the computation of the main inductance is reported on here: The results obtained from a straightforward 3D-FEA model with straightforward settings for coil configuration,

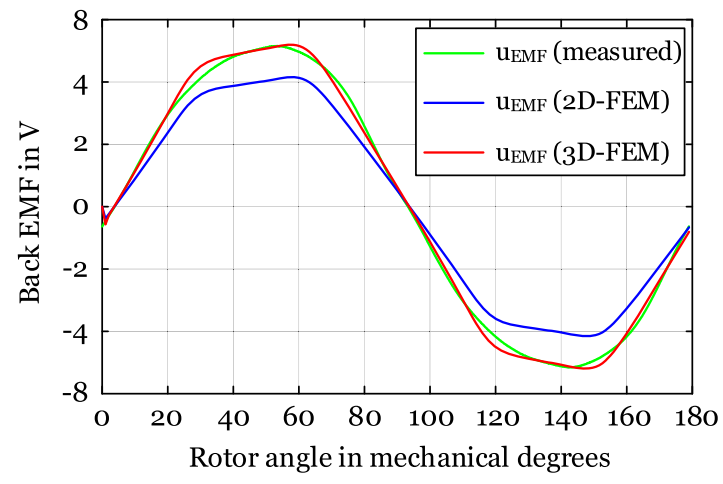

Fig. 8. The back EMF computed with a 2D-FEA model, as well as with a 3D-FEA model, both of which do not consider the winding overhang, differs by $25 \%$ from the measured back EMF; compare also with Fig. 7 [19]

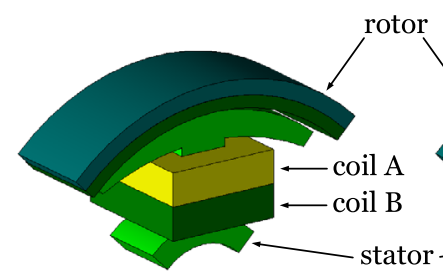

(a)

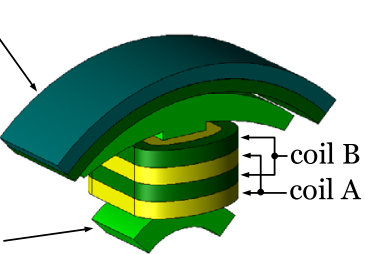

(b)
Fig. 9. Improved modeling of the bifilar winding, whereby the straightforward representation of two lumped windings is replaced by an eight-layer winding; [19]. This measure improved the modeling accuracy by $5 \%$

material settings according to the respective datasheets, and simplified magnet setup, as shown in Fig. 9(a) differ by $47 \%$ from the measured value. The bifilar winding of the example case machine has thus been modeled as an eight layer winding, as shown in Fig. 9(b), and the material parameters of the core back adjusted by data determined experimentally from single core backs, hence, material data that included the manufacturing process. Thereby, the computational error could be reduced to $22 \%$.

\section{Cogging torque reduction}

Cogging torque is a characteristic of permanent-magnet (PM) motors. It describes the interaction between the PM rotor and the slotted stator structure because the former is constantly trying to minimize the reluctance. This results in a typically parasitic no-load torque component. However, cogging torque can cause noise [20, 


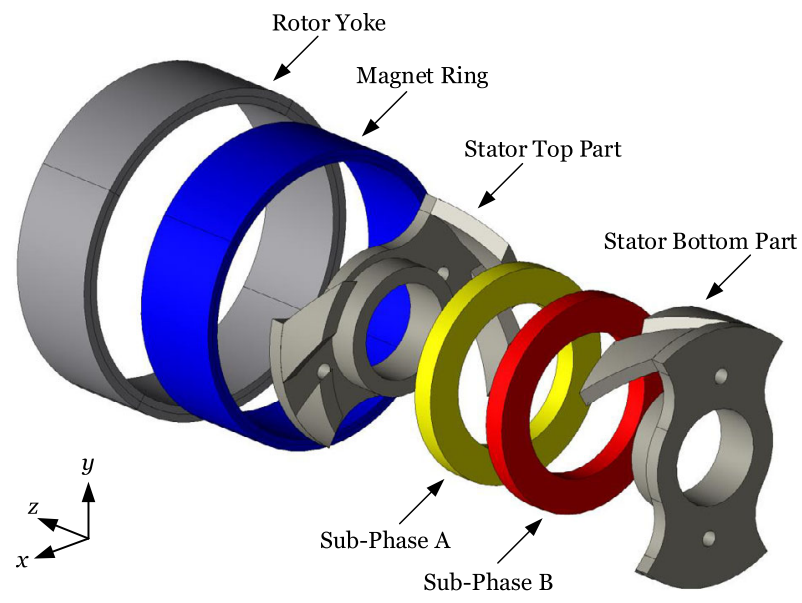

Fig. 10. Exploded view of a low cogging torque single-phase brushless claw-pole motor design [25]

21], as it is superposed upon the alignment torque leading to a torque ripple which can excite system resonances.

The cogging torque strongly depends on (and can be influenced by) factors such as the slot-pole combination, slot width, pole geometry, air-gap length, strength, width, shape, and position of the magnets, magnetization pattern, material properties, manufacturing irregularities, and manufacturing impact. If it remains still too high, despite an optimization of the above mentioned factors, the following cogging torque mitigation methods have been proposed in the literature [22-24]

- implementation of rotor or stator skewing, and

- implementation of dummy slots or teeth.

Being primarily cost-driven, mass-produced FHP motors often have suboptimal slot-pole combinations with a low number of slots and a rather large slot width to facilitate the winding process. Both characteristics lead to high cogging torque and hence a high output torque ripple, which is especially true for low-cost single-phase motors.

However, cogging torque reduction methods such as skewing are hardly applied to mass-produced FHP motors as their implementation usually increases the number of manufacturing steps, the manufacturing complexity, and hence the cost [22]. In an effort to reduce the high cogging torque of low-cost single-phase brushless PM motors, [25] proposed the claw-pole motor design exhibited in Fig. 10. The stator consists of punched and subsequently deep-drawn steel sheets. As opposed to conventional reduction methods, owing to a special punching layout, it is possible to implement both auxiliary slots and stator skewing for cogging torque minimization with no increase to the manufacturing cost.

Figure 11 contrasts the cogging torque of the proposed design (auxiliary slots and skewed claw-poles, see Fig. 10) and that of the baseline design (straight claw-poles, not shown in Fig. 10). In this example, apart from an efficiency reduction of three percentage points (i.e., from 36 to $33 \%$ ), the cogging torque and torque ripple have been successfully reduced by $70 \%$ and $17 \%$, respectively.

The cogging torque of such sub-FHP motors is often in the submilli-Newton meter range, making the measurement a very challenging task. A rheometer-based measurement method has recently been presented (see Fig. 12) to cope with these small torques [26]. In addition, it is also possible to accurately determine the iron losses as well as the hysteresis torque of sub-FHP motors. The fact that said

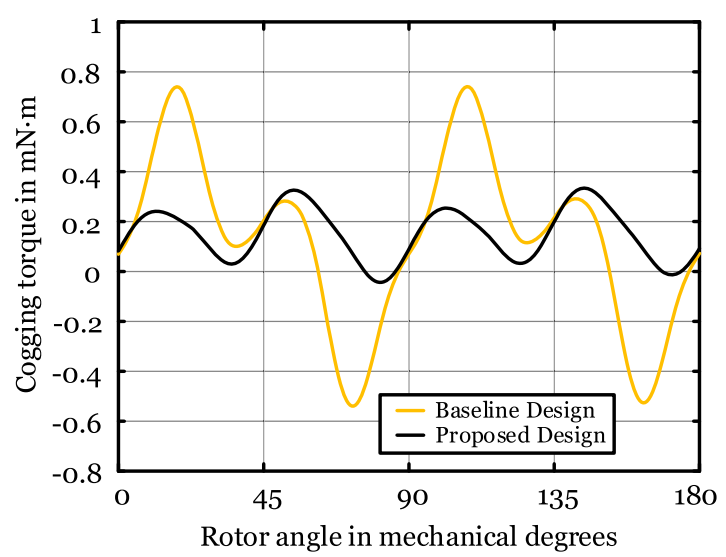

Fig. 11. Measured cogging torque of the baseline design (straight claw-poles, not shown in Fig. 10) and the proposed design (auxiliary slots and skewed stator claws, see Fig. 10)

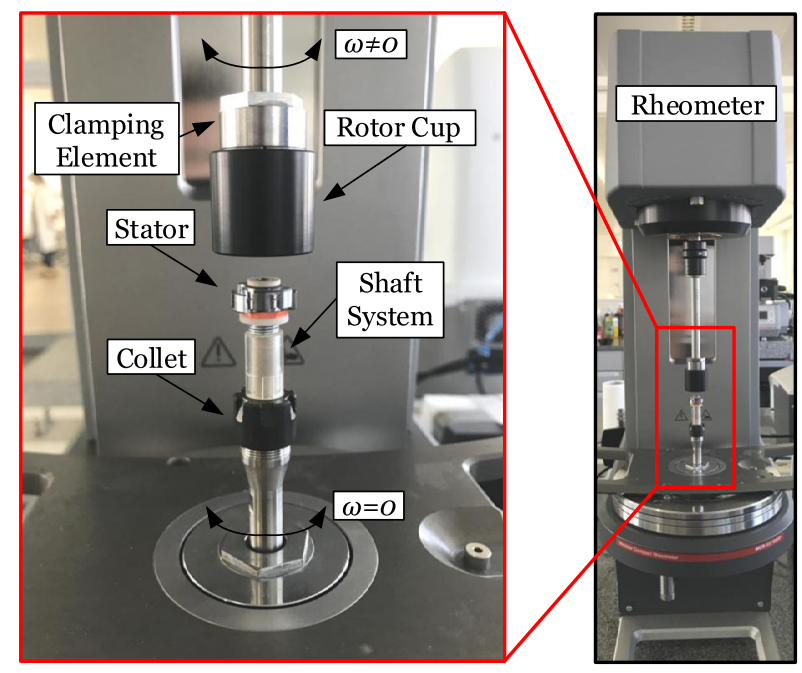

Fig. 12. Cogging torque measurement setup using a rheometer [26]

investigations inherently include all manufacturing influences proves to be advantageous.

\section{Performance improvement through drive control}

In most cases, a PWM approach is used to control the switches of the inverter which drives the brushless motor. Optimizing the switching strategy, performance parameters of the drive, such as the efficiency or the radiated electromagnetic emissions, can be improved, as illustrated in the following.

\subsection{Drive control with delayed turn-on angle}

The seemingly simple refinement of the control of not only advancing the turn-off angle $\alpha_{p}$, but also delaying the turn-on angle $\alpha_{d}$ can lead to significant performance improvements [27]. Such control at the optimal commutation angle combination allows

- reducing copper losses,

- preventing braking torques, and generally

- improving the motor behavior, notably its efficiency. 
Table 4. Performance improvement due to the additional introduction of a delayed turn-on angle $\alpha_{\mathrm{d}}$; example case drive with $\boldsymbol{R}_{\text {phase }}=$ $8.5 \Omega, L_{\mathrm{s}, \text { phase }}=260 \mu \mathrm{H}, L_{\mathrm{m}}=2.8 \mathrm{mH}, U_{\mathrm{dc}}=12 \mathrm{~V}$, and $C=16.6 \mathrm{mF}$, as reported on in [27]

\begin{tabular}{lllll}
\hline $\begin{array}{l}n \\
\text { rpm }\end{array}$ & $\begin{array}{l}I_{\text {peak }} \\
\%\end{array}$ & $\begin{array}{l}I_{\text {rms }} \\
\%\end{array}$ & $\begin{array}{l}P_{\text {cu }} \\
\%\end{array}$ & $\begin{array}{l}\Delta \eta \\
\%\end{array}$ \\
\hline 3000 & -27.4 & -20.9 & -37.4 & 20.6 \\
4000 & -19.8 & -12.4 & -23.3 & 12.8 \\
5000 & -9.8 & -6.2 & -12.0 & 6.8 \\
6000 & -7.6 & -3.9 & -7.6 & 4.5 \\
7000 & -6.3 & -1.9 & -3.8 & 4.5 \\
8000 & -5.9 & -0.8 & -1.6 & 2.2 \\
\hline
\end{tabular}

Exemplarily, Table 4 shows the performance improvements over a wide operating range of a single-phase brushless motor with bifilar winding.

\subsection{Angle modulated switching strategy (AMSS)}

PWM related issues of electromagnetic compatibility have been subject to research for a considerable time. The increase of electric drives used for safety-relevant applications has further enhanced the importance of addressing these aspects.

The problem has, e.g., been addressed by spreading the energy in the frequency spectrum through varying the switching frequency, thus reducing the single peaks [28-31]. Furthermore, as the limits demanded by the standard CISPR25 [32] decrease with higher switching frequencies, reducing the switching frequency can help the device pass the EMC tests [33].

When compared with "larger" drives, FHP and sub-FHP drives have a smaller ratio of supply voltage to phase resistance and thus a smaller short circuit current. Hence, typically, the switching frequency can be significantly reduced without any risk of thermal overload or demagnetization of the magnets. This property is taken advantage of by the so-called "Angle Modulation Switching Strategy" (AMSS), which reduces the switching to its minimum, i.e., the electrical frequency. As a result, only one switching cycle per electrical period is needed. The speed is adjusted by the length of the conduction angle, resulting in a speed-dependent switching period. Thereby, the method differs from the well-established six-step mode of rotating field machines, where the base/fundamental frequency determines the machine's speed.

The switching frequency of the AMSS corresponds to the electrical frequency. Consequently, the switching period is longer than the electrical time constant of the winding. If the on-time is longer than the electrical time constant, the current increases until either the switch is turned off again, or until it reaches its final value determined by the $R-L$ circuit. Thus, the maximum current cannot be controlled, and is higher for AMSS than for the PWM control. Therefore, the low order harmonics are increased and the high order harmonics are decreased in the spectrum of the cable harness current, which is also reflected in the measured conducted emissions, see Fig. 13(a). Although the AMSS increases the conducted emissions in the low frequency range, the span to the limits is still sufficient. The measurement results in Fig. 13 are for measurements with a reduced size of the EMC filter. The number of capacitors on the PCB was reduced from nine to four. The proposed AMSS still passes the EMC test, while the frequency hopping PWM (FHPWM), that has already less emissions than conventional PWM, exceeds the limits.

Due to the bifilar characteristic of the motor winding, the current has very steep edges. Thus, the switching frequency and their har- (a)

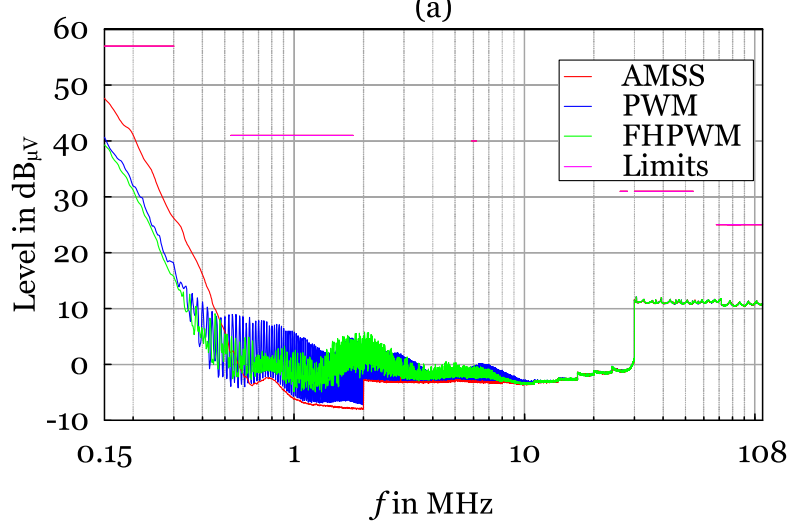

(b)

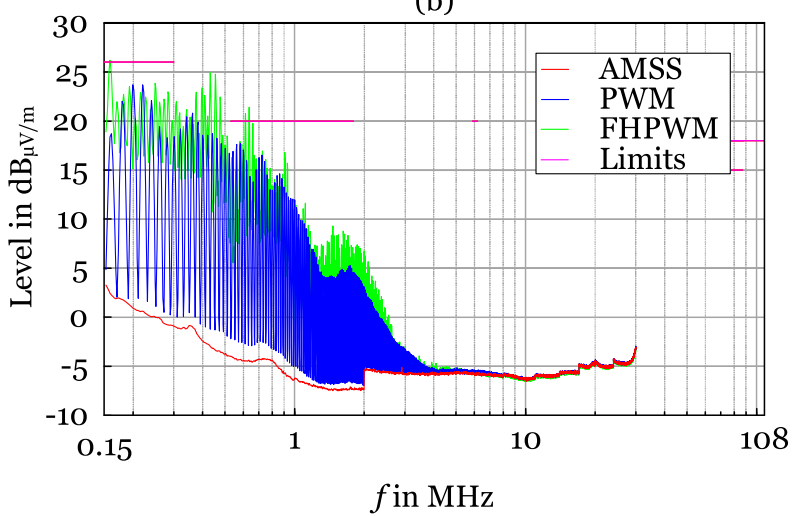

Fig. 13. EMC measurements according to [32] with four instead of nine capacitors on the printed circuit board (PCB), limits CISPR 25 class 5; (a) conducted emissions, quasi peak detector, and (b) radiated emissions, average detector [34]

monics are clearly mirrored in the spectra. The phase current in combination with the phase winding and the PCB are the main sources of the radiated emissions. Figure 13(b) shows the radiated emissions measured according to [32]. The reduced harmonic content in the spectrum of the phase currents decreases the radiated electromagnetic emissions by almost $10 \mathrm{~dB} \mu \mathrm{V} / \mathrm{m}$ in a wide frequency range.

\section{Noise development}

Given the overall noise level reduction in vehicles, the noise development of auxiliary drives has become vitally important [20]. Once hidden by the combustion engine or other dominant noise sources, the noise of automotive pumps and fans may now become disturbing to the passenger. In fact, proper noise standards for auxiliary drives did not exist for a long time and have only recently come into existence. It has been found that the requirements these drives have to meet are becoming more strict. Using a radial fan drive as an example [35], air-borne and structure-borne noise measuring results are shown below.

The air-borne noise measurements of a selected radial fan drive have been performed in a low reflection chamber using a microphone array in accordance with the industrial standard VW 82 469 [36] but at half the specified distance $(0.5 \mathrm{~m}$ instead of $1 \mathrm{~m})$. Figure 14 shows the A-weighted one-third octave band spectrum. Limit 3 presents the maximum sound pressure levels for an auxiliary drive which is automatically operating when the engine is switched off. As can be seen, the range of 1000 to $4000 \mathrm{~Hz}$ is critical because the one-third octave bands are in close proximity to limit 3. 


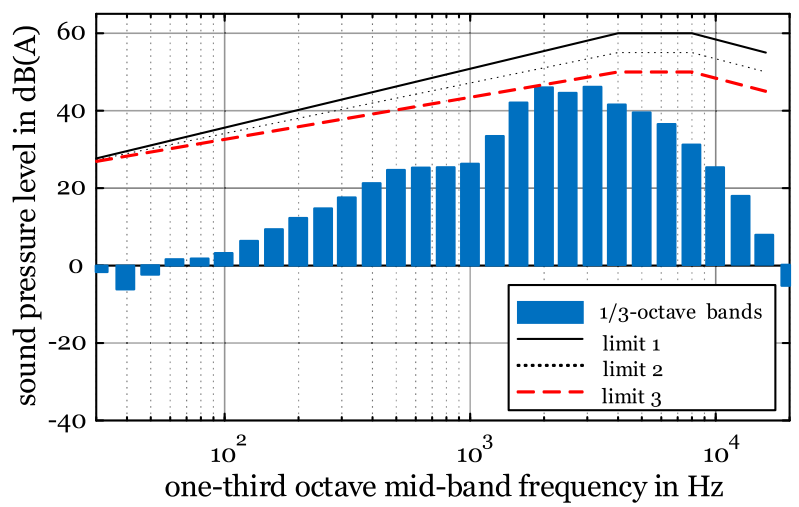

Fig. 14. Measured air-borne noise: one-third octave band spectrum [35]

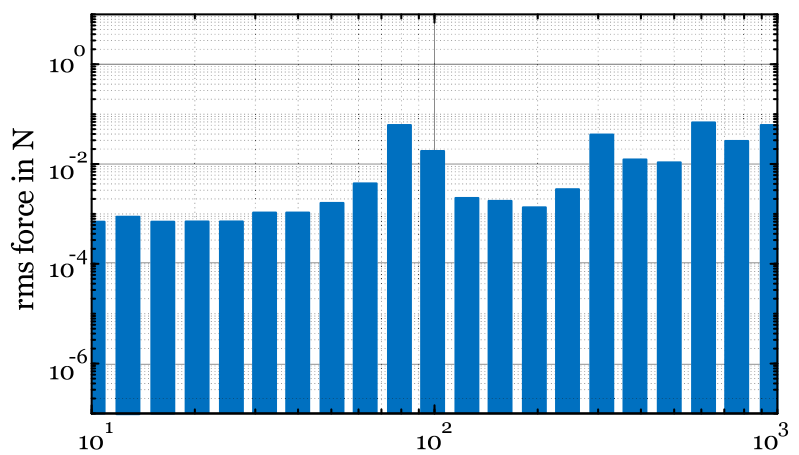

one-third octave mid-band frequency in $\mathrm{Hz}$

Fig. 15. Measured structure-borne noise: one-third octave band spectrum [35]

The structure-borne noise measurements have been performed using three acceleration sensors mounted onto the housing of the same fan drive in the $x-, y-$, and $z$-directions. The one-third octave band spectrum of the total rms force (in which the results of the three axes have been added to yield the total force) is shown in Fig. 15. As can be seen, the fan system under investigation shows several distinct peaks below $1000 \mathrm{~Hz}$.

\section{Summary}

The need for the increased electrification in the automotive industry and constant pressure for performance improvement also affects the multitude of auxiliary drives used in today's passenger cars. From this, a variety of new research problems arises, as the development cycles decrease, manufacturing techniques advance, mitigation of parasitic effects through retrofitting becomes too costly, and energy conversion efficiency continues to gain importance. The particularities of these small drives, such as short time constants, small aspect ratios, and the design for mass-production in most cases do not allow for the direct application of techniques that have been developed for larger machines. This survey paper has provided some examples of different fields of research related to modern FHP and sub-FHP drives. These include design and modeling processes, parasitic effects such as cogging torque, noise development, electromagnetic emissions, and control. The examples mirror the wide area of the research problems that these recent developments in the applications of small drives have brought forward.

\section{Acknowledgements}

Open access funding provided by Graz University of Technology. The financial support by the Austrian Federal Ministry for Digital and Economic Affairs and the National Foundation for Research, Technology and Development is gratefully acknowledged.

Publisher's Note Springer Nature remains neutral with regard to jurisdictional claims in published maps and institutional affiliations.

Open Access Dieser Artikel wird unter der Creative Commons Namensnennung 4.0 International Lizenz veröffentlicht, welche die Nutzung, Vervielfältigung, Bearbeitung, Verbreitung und Wiedergabe in jeglichem Medium und Format erlaubt, sofern Sie den/die ursprünglichen Autor(en) und die Quelle ordnungsgemäß nennen, einen Link zur Creative Commons Lizenz beifügen und angeben, ob Änderungen vorgenommen wurden. Die in diesem Artikel enthaltenen Bilder und sonstiges Drittmaterial unterliegen ebenfalls der genannten Creative Commons Lizenz, sofern sich aus der Abbildungslegende nichts anderes ergibt. Sofern das betreffende Material nicht unter der genannten Creative Commons Lizenz steht und die betreffende Handlung nicht nach gesetzlichen Vorschriften erlaubt ist, ist für die oben aufgeführten Weiterverwendungen des Materials die Einwilligung des jeweiligen Rechteinhabers einzuholen. Weitere Details zur Lizenz entnehmen Sie bitte der Lizenzinformation auf http://creativecommons.org/licenses/by/4.0/deed.de.

References

1. Chowdhury, S., Leitzel, L., Zima, M. (2019): Thermal system for electric vehicles with coolant-based heat pump. ATZ-Elektron. Worldw., 121(5), 48-53.

2. Kunz, A., Kunz, M., Vollert, H., Förster, M. (2018): Electromechanical brake booster for all drive concepts and automated driving. ATZ-Elektron. Worldw., 120(4), 58-61.

3. Hembach, H. (2007): Systematischer Vergleich von BLDC-Motorkonzepten mit Anwendung auf nass laufende Wasserpumpen kleiner Leistung. Ph.D. dissertation, Bundeswehr Universität München, Neubiberg.

4. Reul, A., Fecke, K., Stobrawe, H. (2014): Adjustable oil pump for the lubrication of transmissions. ATZ-Elektron. Worldw., 116(12), 30-35.

5. Hirt, J. (2014): Cooling and dehumidification of LED headlights. ATZ-Elektron. Worldw., 116(5), 36-39.

6. Jordan, M. (2013): With more than 100 actuator motors - The new S-class. Accessed 08 Feb 2019. [Online]. https://blog.mercedes-benz-passion.com/2013/07/ mit-uber-100-kleinen-stellmotoren-die-neue-s-klasse/.

7. Elmos Semiconductor AG (2017): 500mA BLDC motor controller-E523.81. Accessed 22 Oct 2019. [Online]. https://www.elmos.com/produkte/motor-control-ics/ brushless-dc-motor-controller-ic/e52381.html.

8. Marheinke, N., Pinnau, R. (2012): Model hierarchies in space-mapping optimization: feasibility study for transport processes. J. Comput. Methods Sci. Eng., 12(1-2), 6374.

9. Lass, O., Posch, C., Scharrer, G., Volkwein, S. (2011): Space mapping techniques for a structural optimization problem governed by the $\mathrm{p}$-Laplace equation. Optim. Methods Softw., 26(4-5), 617-642.

10. Banda, M. K., Herty, M. (2011): Towards a space mapping approach to dynamic compressor optimization of gas networks. Optim. Control Appl. Methods, 32(3), 253269

11. Redhe, M., Nilsson, L. (2004): Optimization of the new Saab 9-3 exposed to impact load using a space mapping technique. Struct. Multidiscip. Optim., 27(158), 411-420.

12. Bramerdorfer, G., Tapia, J. A., Pyrhönen, J. J., Cavagnino, A. (2019): Modern electrical machine design optimization: techniques, trend, and best practices. IEEE Trans. Ind. Electron., 65(10), 7672-7684.

13. Silber, S., Koppelstätter, W., Weidenholzer, G., Segon, G., Bramerdorfer, G. (2018): Reducing development time of electric machines with SyMSpace. In 2018 8th international electric drives production conference (EDPC) (pp. 1-5).

14. Simpson, T. W. (1998): Comparison of response surface and Kriging models in the multidisciplinary design of an aerospike nozzle. Accessed 22 Oct 2019. [Online] https://ntrs.nasa.gov/archive/nasa/casi.ntrs.nasa.gov/19980046640.pdf.

15. Gruebler, H., Krall, F., Leitner, S., Muetze, A. (2019): Space mapping-based fractional horsepower permanent magnet motor design. In 2019 IEEE international electric machines and drives conference (IEMDC)

16. Gruebler, H., Krall, F., Leitner, S., Muetze, A. (2018): Loss-surface-based iron loss prediction for fractional horsepower electric motor design. In 2018 20th European conference on power electronics and applications (EPE'18 ECCE Europe) (pp. P.1-P.8).

17. Bramerdorfer, G., Andessner, D. (2017): Accurate and easy-to-obtain iron loss model for electric machine design. IEEE Trans. Ind. Electron., 64(3), 2530-2537.

18. Krings, A., Soulard, J. (2010): Overview and comparison of iron loss models for electrical machines. J. Electr. Eng., 10, 162-169. 
19. Kulterer, T. (2019): Investigation of stray paths in fractional horsepower permanentmagnet motors. Master's thesis, Electric Drives and Machines Institute - Graz University of Technology.

20. Zeller, P. (2009): Handbuch Fahrzeugakustik. 2nd ed. Wiesbaden: Vieweg+Teubner.

21. Schwenker, F. (2019): Aspects of high performance flat external rotor motors. In Innovative small drives and micro-motor systems (IKMT) (pp. 152-155).

22. Krishnan, R. (2009): Permanent magnet synchronous and brushless DC motor drives. 1 st ed.

23. Hendershot, J. R., Miller, T. J. E. (2010): Design of brushless permanent-magnet machines. 2nd ed. Venice: Motor Design Books.

24. Gieras, J. F. (2009): Permanent magnet motor technology. 3rd ed. Boca Raton: CRC Press-Taylor and Francis Group.

25. Leitner, S., Gruebler, H., Muetze, A. (2019): Cogging torque minimization and performance of the sub-fractional HP BLDC claw-pole motor. IEEE Trans. Ind. Appl., 55(5), 4653-4664

26. Leitner, S., Krenn, G., Gruebler, H., Muetze, A. (2019): Rheometer-based cogging torque measurement for sub-fractional HP permanent magnet motors. In 2019 IEEE transportation electrification conference and expo (ITEC) (pp. 1-7).

27. Gruebler, H., Leitner, S., Muetze, A., Schoener, G. (2018): Improved switching strategy for a single-phase brushless direct current fan drive and its impact on efficiency. IEEE Trans. Ind. Appl., 54(6), 6050-6059.

28. Chen, J., Jiang, D., Zhao, X. (2018): A comprehensive investigation on conducted EMI reduction for variable switching frequency PWM. In 2018 IEEE international symposium on electromagnetic compatibility and 2018 IEEE Asia-Pacific symposium on electromagnetic compatibility (EMC/APEMC) (pp. 121-126).

\section{Authors}

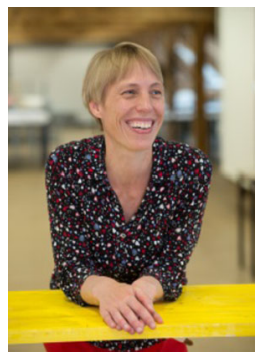

\section{Annette Muetze}

received the Dipl.-Ing. and Ph.D. degrees in electrical engineering and information technology from the Darmstadt University of Technology, Darmstadt, Germany, and the degree in general engineering from Ecole Centrale de Lyon, Ecully, France, both in 1999, and the Dr.-Ing. degree in electrical engineering from the Darmstadt University of Technology, in 2004. She is a Full Professor with the Graz University of Technology, Graz, Austria, where she heads the Electric Drives and Machines Institute and the Christian Doppler Laboratory for Brushless Drives for Pump and Fan Applications. Prior to joining the Graz University of Technology, she was an Assistant Professor at the University of Wisconsin-Madison, Madison, WI, USA, and an Associate Professor at the University of Warwick, Coventry, U.K.

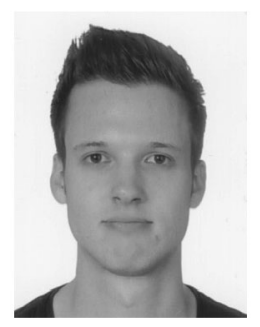

\section{Stefan Leitner}

received the B.Sc. degree and the Dipl.-Ing degree in electrical engineering from Graz University of Technology, Graz, Austria, in 2014 and 2016, respectively. He is currently pursuing his Ph.D. degree in electrical engineering at the Electric Drives and Machines Institute at Graz University of Technology, Graz, Austria. He spent an academic year at the University of Tennessee, Knoxville, USA, in 2014-15, via the International Student Exchange Program (ISEP). He was a visiting scholar at Washington State University, Pullman, WA, USA, and a recipient of the Marshall Plan Scholarship in 2016. He was awarded Oesterreichs Energie-Preis 2017 for his Master's Thesis. His research interests include the design of fractional hp drives, finite element analysis, and microgrids. Mr. Leitner is a member of the Christian Doppler Laboratory for Brushless Drives for Pump and Fan Applications.
29. Chen, X., Zhang, C., Yu, Z., Qu, H., Zhang, E. (2018): A spread spectrum modulation method based on dual-clock for filterless digital class-D audio amplifiers. In 2018 13th IEEE conference on industrial electronics and applications (ICIEA) (pp. 1992-1995).

30. Chen, J.-H., Liu, P.J., Chen, Y. E. (2009): A spurious emission reduction technique for power amplifiers using frequency hopping DC-DC converters. In 2009 IEEE radio frequency integrated circuits symposium (pp. 145-148).

31. Mihali, F., Kos, D. (2006): Reduced conductive EMI in switched-mode DC-DC power converters without EMI filters: PWM versus randomized PWM. IEEE Trans. Power Electron., 21(6), 1783-1794.

32. IEC Std (2016): In CISPR 25:2016 vehicles, boats and internal combustion engines radio disturbance characteristics - limits and methods of measurement for the protection of on-board receivers.. IEC Oct. 2016.

33. Alexandersson, S. (2008): Automotive electromagnetic compatibility - prediction and analysis of parasitic components in conductor layouts. Ph.D. dissertation, Lund University.

34. Krall, F., Gruebler, H., Muetze, A. (2019): Angle modulated switching strategy for frac tional horsepower BLDC motors for improved electromagnetic compatibility. In 2019 21st European conference on power electronics and applications (EPE'19 ECCE Europe) (pp. 1-9).

35. Hofmann, S. (2019): Noise, vibration, and harshness - characteristics of sub-fractional horsepower fan drives. Master's thesis, Electric Drives and Machines Institute - Graz University of Technology.

36. Bielert, F. (2014): Zusatzaggregate - Akustische Anforderungen, Volkswagen Konzernnorm VW 82 469. Volkswagen AG, Jul. 2014

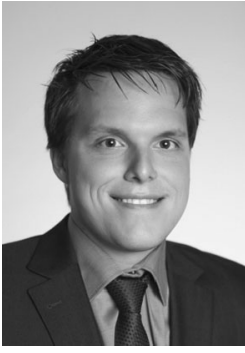

\section{Hannes Gruebler}

received the B.Sc. degree and the Dipl.-Ing. degree in electrical engineering from Graz University of Technology, Graz, Austria, in 2012 and 2016, respectively. He is currently pursuing his Ph.D. degree in electrical engineering at the Electric Drives and Machines Institute at Graz University of Technology, Graz, Austria

His research interests include the systemdesign of small electric drives and their optimization. He is a member of the Christian Doppler Laboratory for Brushless Drives for Pump and Fan Applications.

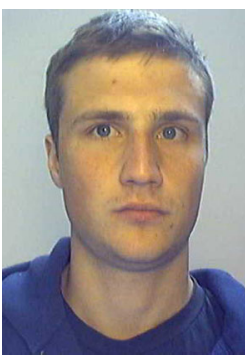

\section{Felix Krall}

received the B.Sc. degree and the Dipl.-Ing degree in electrical engineering from Graz University of Technology, Graz, Austria, in 2015 and 2017, respectively. He is currently working toward the Ph.D. degree in electrical engineering at the Electric Drives and Machines Institute, Graz University of Technology. He is with the Christian Doppler Laboratory for Brushless Drives for Pump and Fan Applications at Graz University of Technology. His research interests include the systems design of fractional hp electric drives and their electromagnetic compatibility. 